\title{
The Influence of Psychological Gender and Coping on Adolescents' Symptom Reports
}

\author{
Anne-Katharina Schmitz ${ }^{1}$, Arnold Lohaus ${ }^{1} \&$ Marc Vierhaus $^{1}$ \\ ${ }^{1}$ Bielefeld University, Germany \\ Correspondence: Anne-Katharina Schmitz, Department of Psychology, Bielefeld University, Germany. E-mail: \\ anne-katharina.schmitz@uni-bielefeld.de
}

\author{
Received: May 23, 2013 \\ Accepted: June 28, $2013 \quad$ Online Published: September 23, 2013 \\ doi:10.5539/jedp.v3n2p30 \\ URL: http://dx.doi.org/10.5539/jedp.v3n2p30
}

This study was supported by a grant from the German Research Foundation (Deutsche Forschungsgemeinschaft).

\begin{abstract}
Health complaints are rather widespread even in children and adolescents. This paper explores the role of psychological gender (feminine and masculine) and coping strategies for the explanation of individual differences in symptom reports. A study with 1.021 children and adolescents aged 9 to 17 showed a significant relation of the coping variables catastrophizing and anger-related emotion regulation to an increase in symptom reports almost throughout the sexes and age groups. There were additional influences of a male gender orientation to decreased symptom reports and of non-pain-related problem solving to increased symptom reports. These effects were, however, restricted to the male subgroup. The meaning of the results for the current well-being and the future coping of children and adolescents with their health complaints is elaborated and discussed.
\end{abstract}

Keywords: somatic symptoms, psychological symptoms, coping, gender role orientation, sex differences, children, adolescents

\section{Introduction}

Although childhood and adolescence are periods of low morbidity rates, health complaints are nevertheless widespread during these ages. One of the most extensive international studies focusing on this subject is the Health Behaviour in School-Age Children Study (HBSC-Study; Currie et al., 2012). Over 200.000 children and adolescents, aged 11 to 15, from 43 countries participated in the study between 2009 and 2010. Apart from being asked about their subjective health status, participants were asked to rate the frequency of their encountered bodily symptoms (e. g. headaches, stomach pains or back aches) over the past six months. A fair or poor health status was reported by $11 \%$ of the 11 -year old participants. This proportion increased to $18 \%$ in 15 -year old adolescents. The increase across age was higher for girls in comparison to boys. Additionally, multiple symptoms were reported by $28 \%$ of the 11 -year old participants, with an increase across age up to $35 \%$ in 15 year-old adolescents. Again, there were sex differences with higher proportions in girls in comparison to boys. The results were rather consistent throughout the participating countries. High prevalence rates for somatic complaints (e.g., headache, backache, abdominal pain) as well as psychological complaints (e.g., nervousness, exhaustion) were also reported in other studies (e.g., Bingefors \& Isacson, 2004; Rhee, Miles, Halpern, \& Holditch-Davis, 2005). Most of these complaints are not related to defined diagnoses or diseases, but to diffuse symptoms. They are nevertheless important, because they influence the present well-being of children and adolescents and also the future health perception and health care utilization in subsequent life periods. Thus, the search for factors underlying health reports in early periods of life may be an important target for research.

According to Macintyre (1993) a possible factor influencing symptom reports may be a female gender role orientation. Children and adolescents with a female gender role orientation may be more willing to report symptoms of distress and illness. Differences in the way that symptoms are perceived, evaluated and acted upon may be a result of childhood socialization in accordance with sex role expectations (Macintyre, 1993; Maccoby, 1998). Because the degree of a female or male self-conception varies within both sexes, individual differences 
regarding the degree of a female or male gender role orientation may influence the identification and willingness to report somatic and psychological symptoms (within each of the sexes).

A second influential factor for symptom reports is related to coping with stress-evoking events. According to Currie et al. (2012) frequent or sustained stress may lead to physiological stress, which in turn can affect the development of complaints. As a consequence, the availability of effective coping skills can be assumed to be an influential variable in the context of health complaints. It should be noted that the coping behaviour might also be influenced by gender role orientations, because specific coping strategies are more or less consistent with gender role expectations (e.g., searching for social support is more in line with a female gender role orientation).

Gijsbers van Wijk and Kolk (1997) have provided a symptom perception model, which differentiates between processes of symptom perception (attention to symptoms, detection of symptoms, attribution of meaning) and symptom related behaviour (e.g., the willingness to report symptoms, coping with symptoms, use of medical services). Both, symptom perception and symptom related behaviour may be influenced by gender role orientations and by coping behaviour. Based on these considerations, the factors addressed in this study are related to (a) gender role orientations and (b) coping behaviour.

\subsection{Gender Role Orientations}

According to Hyde, KrajnikSkuldt-Niederberger (1991) it is socially more acceptable for the female gender to admit weaknesses. This may imply that comparable sensations are reported more frequently and as more intense by females than males. This may not be the result of biological differences, but resulting from socially accepted gender role behaviour (Fillingim et al., 2009). Because females as well as males differ with regard to their degree of identification with traditionally defined sex roles, their psychological gender (female and male self-conception) may differ from their biological sex. This is the reason to assume that gender role orientations may influence symptom reports both across the sexes and within each sex. The identification with one's own gender role orientation increases with age, especially during adolescence, as does the self-concept and identity. As a consequence, this approach can also be applied to explain increasing symptom reports with age as well as increasing sex differences with age.

\subsection{Coping with Pain and Stressful Events}

Available resources for coping with stressful events may be an additional factor for the explanation of differences in symptom reports. There are at least two paths through which coping strategies may influence symptom reports. First, coping may reduce the amount of experienced stress, which in turn may reduce the emergence of stress symptoms. Second, coping strategies can be used to deal with somatic or psychological symptoms. In this case, somatic or psychological symptoms and not stressors are addressed with coping efforts. This may in turn contribute to decreasing the level of strain, because the experience of somatic or psychological symptoms may trigger stress experiences. As a consequence, the current approach differentiates coping strategies used to reduce the general level of experienced stress from coping strategies used specifically to address somatic or psychological symptoms.

Several conceptions have been provided to differentiate between coping strategies used to reduce the general level of experienced stress. Among the most popular distinction is the differentiation between problem-focused and emotion-focused coping (Lazarus \& Folkman, 1984). According to Compas et al. (2001) problem-focused coping is related to acting on the source of stress in the environment, whereas emotion-focused coping is related to palliating negative emotions that arise from a stressful encounter or event. Although a wide variety of coping subtypes have been proposed, the range of subtypes that can be empirically distinguished (e.g., by factor analysis) is much smaller. The range of subtypes varies between three dimensions (e.g., Walker, Smith, Garber, \& van Slyke, 1997) and five dimensions (Connor-Smith et al., 2000). The factor structures have been inconsistent across studies (Compas et al., 2001) and there are no consistent relations to underlying coping conceptualizations (e.g., the problem- and emotion-focused coping distinction).

A coping variable specifically associated with somatic or psychological symptoms is catastrophizing. Catastrophizing refers to the individual tendency to focus on and exaggerate the threat value of a stressful event (Herrmann et al., 2007; Rosenstiel \& Keefe, 1983). Although the conception of catastrophizing was often used in the context of somatic pain (e.g., Sullivan et al., 2001), it is also used in the context of psychological symptoms (e.g., Vasey \& Borkovec, 1992). Catastrophizing in the face of somatic or psychological symptoms is assumed being related to an amplification of the experienced symptoms. A similar conception is rumination. However, whereas catastrophizing means to explicitly focus on the threat of an event, rumination is characterized by a repetitive focus of thoughts on symptoms of distress and an inability to disengage from these thoughts (Nolen-Hoeksema, Stice, Wade, \& Bohon, 2007). According to Hermann et al. (2007), "pain-related cognitions 
and especially pain catastrophizing as compared with other pain coping behaviors are particularly crucial in the development and maintenance of chronic pain" (p. 805). Specific coping skills related to somatic or psychological symptoms may be important influential factors in the context of symptom reports in children and adolescents. As Davidson et al. (2006) point out, coping skills are often overlooked in health related studies but may be an important determinant in connection with health outcomes. Thus in this study, catastrophizing is addressed as a specific coping strategy that may influence somatic and psychological symptom reports. Two additional coping strategies (positive self-statements and problem-solving) are included because in previous studies these strategies were shown to be predictive for pain-related complaints (Herrmann et al., 2007).

This study tries to evaluate the contributions of gender role orientations and coping for the explanation of individual differences in symptom reports. It is - in line with previous studies - expected that sex differences regarding symptom reports exist, which are assumed to increase with age. If this expectation is supported by the data, the subsequent analyses have to be done for both sexes separately. The main assumption underlying these analyses is that gender role orientations and coping strategies can explain individual differences in symptom reports within the groups of female and male children and adolescents (Hypothesis 1). If sex differences regarding symptom reports increase with age, the second Hypothesis is, that the predictive value of psychological gender and coping strategies on symptom reports will also increase with age (Hypothesis 2).

\section{Method}

\subsection{Participants}

Participants were 1.021 children and adolescents (504 male and 517 female) of grades four $(n=150)$, five $(n=156)$, six $(n=193)$, seven $(n=169)$, eight $(n=171)$ and nine $(n=182)$ from 24 German primary and secondary schools. The ages ranged from 9 to 17 , with a mean of $12.6(S D=1.9)$ years. The participating schools covered a broad range of performance levels and can therefore be seen as largely representative samples of children in Germany. All children were Caucasian, from lower to upper middle-class socio-economic backgrounds. The children's participation in the study was on a voluntary basis and required the parents' permission.

\subsection{Measures}

\subsubsection{Somatic and Psychological Symptoms}

The report of several common somatic and psychological symptoms was assessed using a subscale of the German Questionnaire for the Measurement of Stress and Coping in Children and Adolescents (SSKJ 3-8) by Lohaus, Eschenbeck, Kohlmann, and Klein-Hessling (2006). The somatic symptoms scale holds six items (e.g., "How often did you suffer from headaches last week?") and the psychological symptoms scale consists of 12 items (e.g., "How often have you been sad last week?"). Every item had to be answered on a three-point scale (1 $=$ never, 2 = once last week, 3 = several times last week). The symptoms were assessed using a three-point scale, because this scale allowed the participants to indicate the frequency per week. The mean responses across items were used to represent the scale values for somatic and psychological symptoms ( $\alpha=.64$ and .83, respectively).

\subsubsection{Coping in General}

As a non-pain-related coping measure, the coping scales of the SSKJ 3-8 (Lohaus et al., 2006) were applied. The participants were instructed to answer on a five-point scale, ranging from "never" (1) to "almost always" (5) indicating how often they used a variety of coping strategies in an argument situation. In contrast to the symptom ratings, the coping strategies were assessed using a five-point scale, because there was no reference to a specific time interval and because this procedure allows a more differentiated response. Based on previous factor analyses (Lohaus et al., 2006), a total of 30 coping items were presented and assigned to five coping strategies (with six items per coping strategy): seeking social support (e.g., I ask someone for help", $\alpha=.83$ ), problem solving (e.g., I think about how I can solve the problem", $\alpha=.84$ ), avoidance coping (e.g., I pretend as if everything is ok.", $\alpha=.68$ ), palliative emotion regulation (e.g., I try to do something relaxing",$\alpha=.80$ ) and anger-related emotion regulation (e.g., I get angry and slam the door behind me“, $\alpha=.81$ ). All values are in line with the scores reported in the manual of Lohaus et al. (2006) ranging from .70 to .91 . Again, mean values across items were used to represent the scale values for each of the five subscales.

\subsubsection{Pain Related Coping}

Pain related coping was assessed with the Pain-Related Cognitions Questionnaire for Children (PRQ-C; Hermann et al. 2007). Although this instrument focuses on coping with pain-related experiences, it may reflect more general coping tendencies in dealing with symptoms of distress and negative affectivity. The PRQ-C contains three subscales for which the factorial, construct and external validity have been tested in previous studies (Hermann et al., 2007). The catastrophizing scale comprises five items (e.g., "When I am in pain, I think that the pain will never 
stop"). The problem-solving scale holds four items (e.g., "When I am in pain, I figure out what I can do about it") and finally the positive self-statements scale also consists of four items (e.g., "When I am in pain, I say to myself don't worry everything will be ok"). Participants were asked to answer on a five-point-rating scale, ranging from "never" (1) to "always" (5) how often they behaved in such manner, when having to endure pain. For further analyses a mean score was computed for each scale with an internal consistency of $\alpha=.78$ (catastrophizing), $\alpha$ $=.81$ (problem-solving) and $\alpha=.73$ (positive self-statements). All values are in line with those reported by Hermann et al. (2007).

\subsubsection{Psychological Gender}

The gender role orientation was assessed using the German version of the Children's Sex Role Inventory (CSRI, Boldizar, 1991). A total of 10 items commonly associated with femininity (e.g., "I am a kind and caring person") and 10 associated with masculinity (e.g., "I stand up for what I believe in") were presented and their suitability judged on a 6 point-scale ranging from "does not fit at all" (1) to "fits very well" (6). The masculinity scale showed an internal consistency of $\alpha=.81$ and the femininity scale reached $\alpha=.84$. These values are comparable to those reported by Boldizar (1991). The scale values of femininity and masculinity were based on the mean responses across the respective items.

\subsection{Procedure}

Participants were guided to a computer room of the schools, where they were instructed to answer an online questionnaire using Unipark. The completion of the questionnaires took about 15 minutes.

\subsection{Statistical Analyses}

The analysis of sex and age differences in symptom reports is based on multivariate analysis of variance (SPSS 20.0), with sex and age (age groups 9-11, 12-14 and 15-17) as independent variables, and the reports on somatic and psychological symptoms as dependent variables. The analyses for Hypothesis lare based on linear regression analyses (SPSS 20.0). Gender role orientation (female and male orientation) and the pain-related and non-pain-related coping scales were entered into the regression. Multigroup analyses (Amos 20.0) were used to compare the path coefficients of the predictor variables for both sexes. For Hypothesis 2, the effects of the most powerful predictor variables were compared across the different age levels (age groups 9 to 11, 12 to 14 and 15 to17). Again multigroup analyses (Amos 20.0) were applied to compare the path coefficients of the predictor variables across ages. Due to numerous tests used for the analyses, alpha was generally set to $\alpha<.01$.

\section{Results}

\subsection{Sex Differences with Regard to Symptom Reports}

The correlation between psychological and somatic symptom report is $r=.52(p<.001)$. A multivariate analysis of variance to analyze sex and age differences in symptom reports shows a significant multivariate sex difference $\left(F_{(2,1013)}=33.22, p<.001, \eta^{2}=.062\right)$. There are univariate effects for somatic symptoms $\left(F_{(1,1014)}=62.97, p<.001\right.$, $\left.\eta^{2}=.058\right)$, as well as psychological symptoms $\left(F_{(1,1014)}=30.72, p<.001, \eta^{2}=.029\right)$. In both cases, increased numbers of symptoms were reported by girls in comparison to boys. The analysis shows additionally significant multivariate effects for age $\left(F_{(4,2028)}=5.31, p<.001, \eta^{2}=.010\right)$ and for the interaction of sex and age $\left(F_{(4,2028)}=\right.$ $\left.6.40, p<.001, \eta^{2}=.012\right)$. Thus, symptoms as well as sex differences in symptom reports increase with age (Figure 1). The univariate analyses indicate a significant increase of psychological symptoms with age $\left(F_{(2,1014)}=\right.$ $\left.10.59, p<.001, \eta^{2}=.020\right)$. Additionally, there are interactions between sex and age for both symptom scores $\left(F_{(1,1014)}=12.65, p<.001, \eta^{2}=.024\right.$ for somatic and $F_{(4,2028)}=4.78, p<.01, \eta^{2}=.009$ for psychological symptoms). The results support the assumption that sex differences exist for both symptom scores. Moreover, these differences increase with age. In conclusion, these analyses indicate the necessity for separate analyses for the sexes and across age regarding the search for possible influential factors. 


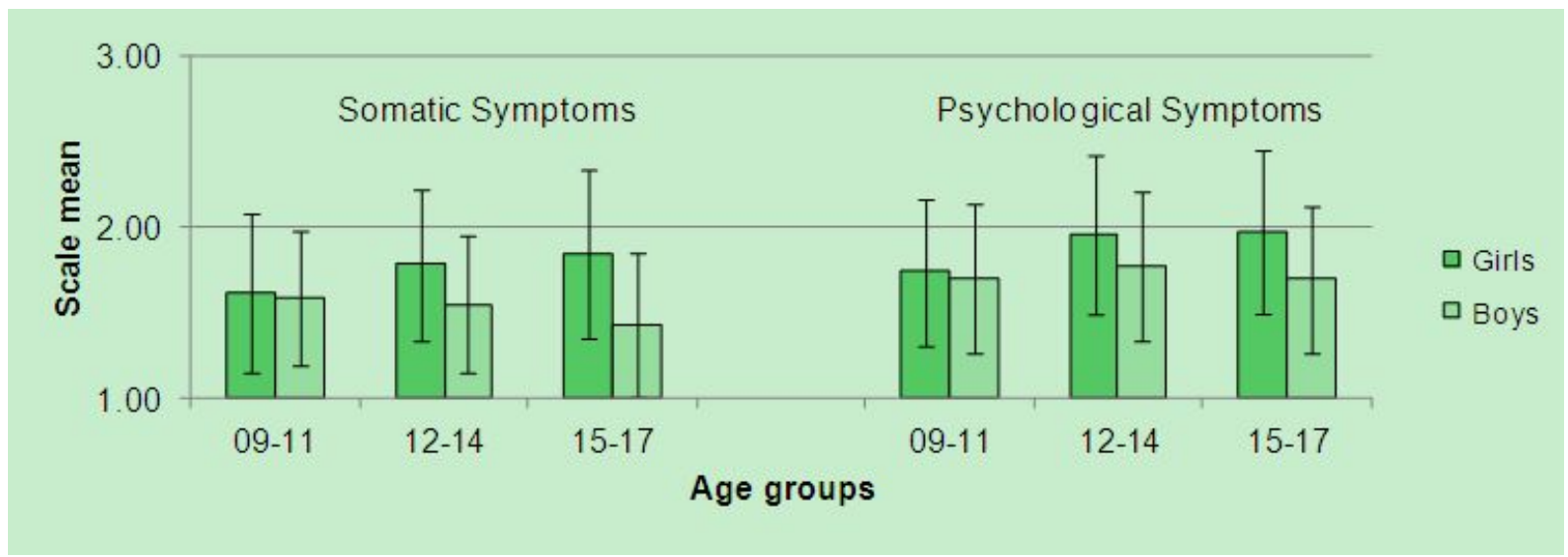

Figure 1. Somatic and psychological symptoms reported by girls and boys aged 9 to 17 years

\subsection{The Role of Psychological Gender and Coping (Hypothesis 1)}

To analyze the role of psychological gender and coping, linear regression analyses were calculated. Gender role orientation and the coping variables were entered into the regression analyses as predictors, the somatic and psychological symptom reports were used as criterion (in separate analyses).

For somatic symptoms in the female sample, the regression analysis shows that $14.4 \%$ of the variance is accounted for by the predictor variables $(\mathrm{F}(10,514)=8.45, \mathrm{p}<.001)$. The main significant contributions come from the coping variables. In particular, catastrophizing $(\beta=.221, \mathrm{p}<.001)$ and anger-related emotion regulation $(\beta=.226, \mathrm{p}<.001)$ are associated with increased somatic symptom reports. With regard to somatic symptoms in the male sample, $18.2 \%$ of the variance is explained by the predictor variables $(\mathrm{F}(10,502)=10.94, \mathrm{p}<.001)$. In this case, a male gender orientation is associated with decreased symptom reports $(\beta=-.127, p=.009)$, whereas catastrophizing is associated with increased symptom reports $(\beta=.342, \mathrm{p}<.001)$. These results are summarized in Table 1.

Table 1. The prediction of somatic symptom reports by gender-role orientation, pain-related coping and non-pain-related coping

\begin{tabular}{lccccccccc}
\hline & \multicolumn{7}{c}{ Female sample } & \multicolumn{7}{c}{ Male sample } \\
\hline & B & SE & $\beta$ & $\mathrm{p}$ & $\mathrm{B}$ & $\mathrm{SE}$ & $\beta$ & $\mathrm{p}$ \\
\hline & & & & & & & & \\
Female role orientation & .009 & .033 & .014 & $>.01$ & .016 & .025 & .033 & $>.01$ \\
Male role orientation & .031 & .030 & .050 & $>.01$ & -.063 & .024 & -.127 & $<.01$ \\
Catastrophizing & .116 & .027 & .221 & $<.001$ & .176 & .026 & .342 & $<.001$ \\
Pain-related problem solving & -.007 & .031 & -.011 & $>.01$ & -.030 & .025 & -.030 & $>.01$ \\
Positive self-statements & -.040 & .025 & -.076 & $>.01$ & -.019 & .020 & -.045 & $>.01$ \\
Seeking social support & -.018 & .024 & -.034 & $>.01$ & -.012 & .023 & -.026 & $>.01$ \\
Problem solving (non-pain-related) & .032 & .031 & .054 & $>.01$ & .002 & .025 & .005 & $>.01$ \\
Avoidant coping & .023 & .032 & .035 & $>.01$ & .022 & .025 & .041 & $>.01$ \\
Palliative emotion regulation & -.021 & .024 & -.039 & $>.01$ & -.007 & .020 & -.015 & $>.01$ \\
Anger-related emotion regulation & .122 & .025 & .226 & $<.001$ & .050 & .019 & .114 & $>.01$ \\
\hline
\end{tabular}

Note. For the female sample: $\mathrm{R} 2=.14(\mathrm{p}<.001)$. For the male sample: $\mathrm{R} 2=.18(\mathrm{p}<.001)$.

For psychological symptoms in the female sample, $25.7 \%$ of the variance is explained by the predictors $(\mathrm{F}(10,514)=17.47, \mathrm{p}<.001)$. Increased symptom reports are associated with catastrophizing $(\beta=.137, \mathrm{p}=.004)$ 
and anger-related emotion regulation $(\beta=.460, \mathrm{p}<.001)$. The respective analysis for the male sample provides $20.6 \%$ of explained variance $\left(F_{(10,502)}=12.78, p<.001\right)$. In this case, the coping variables catastrophizing $(\beta$ $=.250, p<.01)$, anger-related emotion regulation $(\beta=.335, p<.01)$ and non-pain-related problem solving $(\beta$ $=.142, p=.008)$ are associated with increased symptom reports (s. Table 2 ).

Table 2. The prediction of psychological symptom reports by gender-role orientation, pain-related coping and non-pain-related coping

\begin{tabular}{lccccccccc}
\hline & \multicolumn{7}{c}{ Female sample } & \multicolumn{7}{c}{ Male sample } \\
\hline & $B$ & $S E$ & $\beta$ & $p$ & $B$ & $S E$ & $\beta$ & $p$ \\
\hline & & & & & & & & \\
Female role orientation & .012 & .031 & .018 & $>.01$ & -.003 & .027 & -.005 & $>.01$ \\
Male role orientation & .003 & .028 & .004 & $>.01$ & -.004 & .026 & -.007 & $>.01$ \\
Catastrophizing & .071 & .025 & .137 & $<.01$ & .139 & .028 & .250 & $<.001$ \\
Pain-related problem solving & -.028 & .029 & -.045 & $>.01$ & -.021 & .027 & -.041 & $>.01$ \\
Positive self-statements & .008 & .023 & .015 & $>.01$ & -.023 & .021 & -.049 & $>.01$ \\
Seeking social support & -.020 & .023 & -.038 & $>.01$ & -.040 & .024 & -.080 & $>.01$ \\
Problem solving (non-pain-related) & .023 & .029 & .039 & $>.01$ & .069 & .026 & .142 & $<.01$ \\
& & & & & & & & \\
Avoidant coping & -.016 & .030 & -.024 & $>.01$ & .014 & .026 & .024 & $>.01$ \\
& & & & & & & & \\
Palliative emotion regulation & -.005 & .023 & -.010 & $>.01$ & -.046 & .021 & -.095 & $>.01$ \\
Anger-related emotion regulation & .247 & .023 & .460 & $<.001$ & .158 & .021 & .335 & $<.001$ \\
\hline
\end{tabular}

Note. For the female sample: $R^{2}=.26(p<.001)$. For the male sample: $R^{2}=.21(p<.001)$.

To summarize, catastrophizing appears as the most relevant and consistent influential variable. Additionally, anger-related emotion regulation is an influential variable in most analyses. Both variables are related to coping and are associated with increased symptom reports. With restriction to the male sample, a male gender role orientation is relevant and is associated with decreased somatic symptom reports, whereas non-pain-related problem solving is related to increased psychological symptom reports.

Multigroup analyses were used to compare the path coefficients of the ten predictors of somatic and psychological symptoms between the female and male samples. The results of these model comparisons showed no sex differences regarding the prediction of somatic symptoms $\left(\chi_{\text {diff }}^{2}=17.27, d f=10, p=.07\right)$ as well as of psychological symptoms $\left(\chi_{\text {diff }}^{2}=15.50, d f=10, p=.12\right)$. Thus, although there were some differences with regard to specific influential factors, the main structure is similar within the groups of girls and of boys. This is the reason not to differentiate by sex in the following analysis of age effects.

\subsection{Age Differences and Their Role for the Explanation of Symptom Reports (Hypothesis 2)}

The following section compares the influences of the most powerful factors for the explanation of the symptom reports across age groups. The focus lies on those factors, which have proven to be powerful factors in the previous analyses for somatic as well as psychological symptoms (catastrophizing, anger-related emotion regulation, non-pain-related problem solving and a male role orientation). The results of age-separated regression analyses for these factors are depicted in Table 3. 
Table 3. The role of the most powerful predictor variables for somatic symptom reports in different age groups: Results of regression analyses

\begin{tabular}{|c|c|c|c|c|c|c|c|c|}
\hline & \multicolumn{4}{|c|}{ Somatic symptoms } & \multicolumn{4}{|c|}{ Psychological symptoms } \\
\hline & $B$ & $S E$ & $\beta$ & $p$ & $B$ & $S E$ & $\bar{\beta}$ & $P$ \\
\hline \multicolumn{9}{|l|}{ Age 9-11 years $(n=316)$} \\
\hline Male role orientation & -.018 & .028 & -.034 & $>.01$ & -.038 & .028 & -.073 & $>.01$ \\
\hline Catastrophizing & .141 & .028 & .284 & $<.001$ & .098 & .028 & .197 & $<.01$ \\
\hline Non-pain-related problem solving & -.021 & .027 & -.042 & $>.01$ & .008 & .027 & .016 & $>.01$ \\
\hline Anger-related emotion regulation & .110 & .027 & .228 & $<.001$ & .157 & .027 & .326 & $<.001$ \\
\hline \multicolumn{9}{|l|}{ Age $12-14$ years $(n=496)$} \\
\hline Male role orientation & -.038 & .026 & -.065 & $>.01$ & .005 & .025 & .009 & $>.01$ \\
\hline Catastrophizing & .153 & .023 & .289 & $<.001$ & .121 & .023 & .218 & $<.001$ \\
\hline Non-pain-related problem solving & .021 & .023 & .040 & $>.01$ & .034 & .023 & .063 & $>.01$ \\
\hline Anger-related emotion regulation & .088 & .022 & .180 & $<.001$ & .206 & .022 & .403 & $<.001$ \\
\hline \multicolumn{9}{|l|}{ Age $15-17$ years $(n=203)$} \\
\hline Male role orientation & -.049 & .044 & -.077 & $>.01$ & -.026 & .040 & -.044 & $>.01$ \\
\hline Catastrophizing & .181 & .040 & .316 & $<.001$ & .055 & .037 & .102 & $>.01$ \\
\hline Non-pain-related problem solving & .055 & .041 & .093 & $>.01$ & .080 & .038 & .144 & $>.01$ \\
\hline Anger-related emotion regulation & .021 & .042 & .035 & $>.01$ & .203 & .039 & .361 & $<.001$ \\
\hline
\end{tabular}

Note. $R^{2}=.19, R^{2}=.16$, and $R^{2}=.13$ for somatic symptoms, $R^{2}=.20, R^{2}=.26, R^{2}=.17$ for psychological symptoms in age groups $9-11,12-14$ and $15-17$, respectively.

Catastrophizing and anger-related emotion regulation are powerful variables throughout the age groups, although for the oldest age group the role of both variables seems to be differential for somatic and psychological symptom reports. The other variables (non-pain-related problem solving and a male role orientation) seem not to be relevant influential factors, if the age groups are differentiated. The multigroup analyses to compare the path coefficients across the age groups showed insignificant differences for somatic $\left(\chi^{2}{ }_{\text {diff }}=.36, d f=4, p=.99\right)$ as well as psychological symptoms $\left(\chi_{d i f f}^{2}=4.77, d f=4, p=.31\right)$. Thus, the general pattern of the results seems to be rather consistent not only across the sexes, but also across the included age groups.

\section{Discussion}

The results of the present study reveal sex differences in somatic, as well as in psychological symptom reports for the examined age ranges of participants. In general, girls reported more symptoms than boys. As was expected, the symptoms reported increased with age. For psychological symptoms, the increase was larger in girls than boys. For somatic symptoms there was again an increase for girls, but a decrease for boys. In line with previous research, the sex differences increased across age for both symptom categories (e.g., Compas et al., 2001; MacLean, Sweeting, \& Hunt, 2010).

Therefore, it was analyzed whether individual differences in symptom reports might be explained by gender role orientations and coping variables. With a focus on the social gender role an influence on both symptom categories had been expected. Feminine personality traits are associated with a high expressiveness (Fernández \& Coello, 2010) and femininity in general corresponds with greater willingness to admit weaknesses and pain (Robinson et al., 2001). Therefore, a female gender role orientation was expected to be associated with increased symptom reports, regardless of the symptom category. Masculinity on the other hand, is associated with attributes like e.g., independence, self-reliance, strength and toughness (Courtenay, 2000) and is expected to have an attenuating impact on the frequency of reported health complaints. The identification with one's own gender role increases over time, especially during adolescence. The somatic symptom reports in boys showed an obvious decrease with age. This seems to be at least partly influenced by the masculine gender role orientation. A direct effect of a masculine gender role orientation was indeed restricted to the male sample and to somatic 
symptoms. This result underlines that male children and adolescents with a male self-conception interpret their health status in a more positive fashion, whilst suffering from less discomforts and health complaints. The development of a sensitivity regarding health-related symptoms and a readiness to report the latter could therefore be seen as a possible protective factor to identify possible health hazards early enough to be able to prevent serious illnesses.

The strongest predictors for symptom reports were the coping variables focusing on catastophizing and anger-related emotion regulation. This stresses the importance of coping with stress and somatic or psychological symptoms for the overall self-reported health status. One important coping variable seems to be catastrophizing, which may negatively influence body perception. This is underlined by Hermann et al. (2007), who found correlations between pain-related catastrophizing and non-pain-related complaints, like dysphoric moods. According to Sullivan et al. (2001) catastrophizing has a maladaptive effect, due to an enhanced attention to signals of discomfort. Catastrophizing might also have an effect on memory processes because meaningful and emotionally charged situations are elaborated with a higher priority and are retrieved more easily. In addition, a tendency to catastrophize could directly influence the responses in a symptom questionnaire. This means that the confrontation with symptom items could elicit catastrophizing thoughts, which would increase the tendency to report symptoms. It should, however, be noted that the data of this study are based on a cross-sectional design, which does not allow identifying causal directions. As a consequence, it is also possible that catastrophizing thoughts result from the experience of symptoms. Therefore, it is possible that vicious circles between catastrophizing and symptom reports might exist.

The second coping style, which influenced symptom reports, was anger-related emotion regulation (related to externalizing feelings of anger; Eschenbeck, Kohlmann, \& Lohaus, 2007). Negative affectivity is a well-known influential factor for the enhancement of symptom reports (Van Diest et al., 2005; Gijsbers van Wijk \& Kolk, 1997). The question, however, arises whether the appearance of such anger emotions actually leads to an increase in symptoms, or whether the symptom increase in fact results from uncontrollable externalisation of these emotions.

A third coping variable which, however, was restricted to the male subgroup was non-pain-related problem solving. At first glance, it is difficult to understand why problem solving should be related to increased symptom reports. It should, however, be kept in mind that the cross-sectional design of this study does not allow causal conclusions. Thus, it is also possible that male children and adolescents experiencing psychological symptoms show a preference for problem solving strategies to decrease their strain. A similar result was shown in a study of Hoffman, Levy-Shiff, Sohlberg, and Zarizki (1991) who also found an association between problem-focused coping and increased symptom reports.

With respect to Hypothesis 2, the four strongest predictors for the symptom reports were analyzed regarding their influence in the different age groups. Catastrophizing and anger-related emotion regulation proved to be strong predictors for somatic as well as psychological symptoms throughout all age groups. Nevertheless, their pattern of influence varied depending on the symptoms categories. The catastrophizing variable was, in relation to somatic symptoms, more powerful whereas, on the other hand, the psychological symptoms are influenced more by anger-related emotion regulation. This differential influence is growing across age and reaches its maximum in the oldest subgroup: At an age of 15 to 17, catastrophizing influences only somatic complaints, whereas the influence of anger-related emotion regulation is restricted to psychological complaints.

As a consequence, catastrophizing and anger-related emotion regulation seem to be important factors, which are associated with increased somatic and psychological symptom reports. It should be emphasized that catastrophizing and anger-related emotion regulation are - in contrast to biological sex - variables that can be influenced by educational efforts. It is, however, necessary to clarify the causal direction of the relation between coping and symptom reports, before educational efforts may be suggested to support children and adolescents in reducing catastrophizing and anger-related emotion regulation. During adolescence, the importance of biological sex seems to increase in addition to the coping variables. However, biological founded differences in anatomy, chromosomes and hormones cannot provide a satisfactory explanation (Davidson et al., 2006). Thus, it remains necessary to search for the underlying factors, which could explain these biological sex differences and their link to symptom reports.

A possible limitation of this study may be related to the restricted focus on gender role orientations and coping variables. It seems reasonable that additional variables have to be taken into account, which may provide further explanations for the individual differences in symptom reports. For example, several studies showed strong relationships between the health behavior of children and their parents (e.g., Harvey, Curry, \& Brad, 1991; 
Rossow \& Rise, 1994; Wickrama, Conger, Wallace, \& Elder, 1999). As a consequence, the modeling and educational behavior of parents can be an important factor for the transmission of a differential health-related behavior of girls and boys. Future research should therefore include additional variables, to understand individual differences in symptom reports.

\section{References}

Bingefors, K., \& Isacson, D. (2004). Epidemiology, co-morbidity, and impact on health-related quality of life of self-reported headache and musculoskeletal pain - A gender perspective. European Journal of Pain, 8(5), 435-450. http://dx.doi.org/10.1016/j.ejpain.2004.01.005.

Boldizar, J. P. (1991). Assessing sex typing and androgyny in children: The Children's Sex Role Inventory. Developmental Psychology, 27(3), 505-515. http://dx.doi.org/10.1037/0012-1649.27.3.505.

Compas, B. E., Connor-Smith, J. K., Saltzman, H., Harding Thomsen, A., \& Wadsworth, M. E. (2001). Coping with stress during childhood and adolescence: Problems, progress, and potential in theory and research. Psychological bulletin, 127(1), 87-127. http://dx.doi.org/10.1037/0033-2909.127.1.87.

Connor-Smith, J., Compas, B. E., Wadsworth, M. E., Harding Thomsen, A., \& Saltzman, H. (2000). Responses to stress in adolescence: Measurement of coping and involuntary stress responses. Journal of Consulting and Clinical Psychology, 68(6), 976-992. http://dx.doi.org/10.1037/0022-006X.68.6.976.

Courtenay, W. H. (2000). Constructions of masculinity and their influence on men's well-being: A theory of

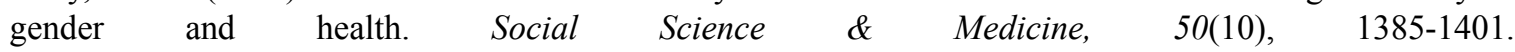
http://dx.doi.org/10.1016/S0277-9536(99)00390-1.

Currie, C., Zanotti, C., Morgan, A., Currie, D., de Looze, M., Roberts, C., Samdal, O., Smith, O. R. F., \& Barnekow, V. (2012). Social determinants of health and well-being among young people. World Health Organization Regional Office for Europe.

Davidson, K. W., Trudeau, K. L., van Roosmalen, E., Steward, M., \& Kirkland, S. (2006). Gender as a health determinant and implications for health education. Health Education and Behavior, 33(6), 731-743. http://dx.doi.org/10.1177/1090198106288043.

Eschenbeck, H., Kohlmann, C.-W., \& Lohaus, A. (2007). Gender differences in coping strategies in children and adolescents. Journal of Individual Differences, 28(1), 18-26. http://dx.doi.org/10.1027/1614-0001.28.1.18.

Fernández, J., \& Coello, M. T. (2010). Do the BSRI and PAC really measure masculinity and femininity? The Spanish Journal of Psychology, 13(2), 1000-1009.

Fillingim, R. B., King, C. D., Ribeiro-Dasilva, M. C., Rahim-Williams, B., \& Riley III, J. L. (2009). Sex, Gender, and Pain: A Review of Recent Clinical and Experimental Findings. The Journal of Pain, 10(5), 447-485. http://dx.doi.org/10.1016/j.jpain.2008.12.001.

Gijsbers van Wijk, C. M. T., \& Kolk, A. M. (1997). Sex differences in physical symptoms: The contribution of symptom perception theory. Social Science \& Medicine, 45(2), 231-246. http://dx.doi.org/10.1016/S0277-9536(96)00340-1.

Harvey, D. M., Curry, C. J., \& Brad, J. H. (1991). Individuation and intimacy in intergenerational relationships and health: Patterns across two generations. Journal of Family Psychology, 5(2), 204-236. http://dx.doi.org/10.1037/0893-3200.5.2.204.

Hermann, C., Hohmeister, J., Zohsel, K., Ebinger, F., \& Flor, H. (2007). The assessment of pain coping and pain-related cognitions in children and adolescents: Current methods and further development. The Journal of Pain, 8(10), 802-813. http://dx.doi.org/10.1016/j.jpain.2007.05.010.

Hoffman, M. A., Levy-Shiff, R., Sohlberg, S. C., \& Zarizki, J. (1991). The impact of stress and coping: Developmental changes in the transition to adolescence. Journal of Youth and Adolescence, 21(4), 451-469. http://dx.doi.org/10.1007/BF01537897.

Hyde, J. S., Krajnik, M., \& Skuldt-Niederberger, K. (1991). Androgyny across life span: A replication and $\begin{array}{llll}\text { longitudinal Follow-Up. Developmental } & \text { Psychology, }\end{array}$ http://dx.doi.org/10.1037/0012-1649.27.3.516.

Lazarus, R. S., \& Folkman, S. (1984). Stress, appraisal, and coping. Springer Publishing Company. http://dx.doi.org/10.1007/978-1-4419-1005-9.

Lohaus, A., Eschenbeck, H., Kohlmann, C.-W., \& Klein-Heßling, J. (2006). Fragebogen zur Erhebung von 
Stress und Stressbewältigung im Kindes- und Jugendalter (SSKJ 3-8) (Questionnaire for the Measurement of Stress and Coping in Children and Adolescents).Göttingen: Hogrefe.

MacLean, A., Sweeting, H., \& Hunt, K. (2010). Rules for boys, guidelines for girls. Gender differences in symptom reporting during childhood and adolescence. Social Science \& Medicine, 70(4), 597-604. http://dx.doi.org/10.1016/j.socscimed.2009.10.042.

Maccoby, E. E. (1998). The two sexes: Growing up apart, coming together. Harvard University Press.

Macintyre, S. (1993). Gender differences in the perceptions of common cold symptoms. Social Science \& Medicine, 36(1), 15-20. http://dx.doi.org/10.1016/0277-9536(93)90301-J.

Nolen-Hoeksema, S. Stice, E., Wade, E., \& Bohon, C. (2007). Reciprocal relations between rumination and bulimic, substance abuse, and depressive symptoms in female adolescents. Journal of Abnormal Psychology, 116(1), 198-207. http://dx.doi.org/10.1037/0021-843X.116.1.198.

Rhee, H., Miles, M. S., Halpern, C. T., \& Holditch-Davis, D. (2005). Prevalence of recurrent physical symptoms in U.S. adolescents. Pediatric Nursing, 31(4), 314-319.

Robinson, M. E., Riley III, J. L., Myers, C. D., Papas, R. K., Wise, E. A., Waxenberg, L. B., \& Fillingim, R. B. (2001). Gender Role Expectations of Pain: Relationship to Sex Differences in Pain. The Journal of Pain, 2(5), 251-257. http://dx.doi.org/10.1054/jpai.2001.24551.

Rosenstiel, A. K., \& Keefe, F. J. (1983). The use of coping strategies in chronic low back pain patients: Relationship to patient characteristics and current adjustment. Pain, 17(1), 33-44. http://dx.doi.org/10.1016/0304-3959(83)90125-2.

Rossow, I., \& Rise, J. (1994). Concordance of parental and adolescent health behaviors. Social Science and Medicine, 38(9), 1299-1305. http://dx.doi.org/10.1016/0277-9536(94)90193-7.

Sullivan, M. J. L., Thorn, B., Haythornthwaite, J. A., Keefe, F., Martin, M., Bradley, L. A., \& Lefebvre, J. C. (2001). Theoretical Perspectives on the Relation Between Catastrophizing and Pain. The Clinical Journal of Pain, 17(1), 52-64.

Van Diest, I., De Peuter, S. D., Eertmans, A., Bogaerts, K., Victoir, A., \& Van den Bergh, O. (2005). Negative affectivity and enhanced symptom reports: Differentiating between symptoms in men and women. Social Science \& Medicine, 61(8), 1835-1845. http://dx.doi.org/10.1016/j.socscimed.2005.03.031.

Vasey, M. W., \& Borkovec, T. D. (1992). A catastrophizing assessment of worrisome thoughts. Cognitive Therapy and Research, 16, 505-520. http://dx.doi.org/10.1007/BF01175138.

Walker, L. S., Smith, C. A., Garber, J., \& Van Slyke, D. A. (1997). Development and validation of the Pain Response Inventory for Children. Psychological Assessment, 9(4), 392-405. http://dx.doi.org/10.1037/1040-3590.9.4.392.

Wickrama, K. A. S., Conger, R. D., Wallace, L. E., \& Elder, G. H. (1999). The intergenerational transmission of health-risk behaviors: Adolescent lifestyles and gender moderating effects. Journal of Health and Social Behavior, 40(3), 258-271.

\section{Copyrights}

Copyright for this article is retained by the author(s), with first publication rights granted to the journal.

This is an open-access article distributed under the terms and conditions of the Creative Commons Attribution license (http://creativecommons.org/licenses/by/3.0/). 